\title{
Bi-Directional Feedback to the Welfare State and Public Opinion
}

Nate Breznau, University of Bremen, breznau.nate@gmail.com

\begin{abstract}
Policy feedback between public opinion and social policy is likely bi-directional. At least theory suggests. However, most research uses a uni-directional model. By conceiving the relationship as bidirectional it is possible to extend Pierson's increasing returns theory to the neoliberal era, mostly after the 1980s, when welfare states of the rich democracies saw many forms of retrenchment. By testing a bi-directional theory using bi-directional models, this paper argues that public opinion likely updated in response to retrenchment and contributes to a new lock-in effect of institutionalized retrenchment paths. The models use ISSP data and a measure of the size of the welfare state based on SOCX spending data combined with a neoliberal indicator form the Fraser institute for the period 1990-2016 across the rich democracies for which data are available.
\end{abstract}




\section{Public Opinion And Social Policy Feedback}

Since the $19^{\text {th }}$ Century human history is witness to the global emergence of welfare states (Schmitt et al., 2015). Paul Pierson adapted the economic concept of increasing returns to describe the role of public opinion in this process. The Industrial Revolution, expansion of citizenship and the first social protection laws transformed the working masses into 'clients' of the state. As such, policymakers capitalized on working-classes' interests to gain votes by increasing welfare provisions (Pierson, 1998, 2000). Pierson's increasing returns arguments became a foundational theory to describe the Golden Age of welfare states in the study of social policy and a fundamental tenet of policy feedback research (Béland and Schlager, 2019).

After the Industrial Revolution, Pierson argues that opinion and policy contributed to institutional path dependency because of their endogeneity (see also Campbell, 2012). Public opinion essentially 'locks in' a certain path trajectory. For example, cutbacks to social policy increase support for the welfare state, because they increase the gap between what the public wants and what it gets, thus reinforcing this path (Pierson, 1996, p. 156). Soroka and Wlezien (2010) refer to this gap as the public's "relative preferences" and results from their time-series models suggests it creates an equilibrium between public preferences and policymaking. Their findings are strong evidence in support of Pierson's increasing returns arguments - that policies departing from a given institutional social policy trajectory will be corrected by public opinion responses in the form of 'negative' feedback, leading to the so called 'lock in' effect. Pierson's theory of increasing returns explains why social policies continually expanded albeit along discrete trajectories after their inceptions. Pierson also uses this argument in theorizing that cutbacks to the welfare state were lesser than one would expect given the neoliberal ideological watershed among governments in the 1980s and 90s.

The language in older literature on this subject leads to much confusion, therefore Busemeyer and colleagues (2019) suggest a new set of labels. In particular, they distinguish between direction of 
feedback (accelerating, self-reinforcing and self-undermining), the scope (general or specific) and the time it takes to actualize (long- or short-term). Their array of types within each of these three components of feedbacks are all interrelated and take place in general and in specific areas, leading to quite a complex theoretical picture of reality. Following the language of Busemeyer et al (2019, Table 1) accelerating feedback is a case of "policies creating support for further expansion". However, there is no a priori reason to assume that the public can only be motivated to support further expansions. As noted by Skocpol and Williamson (2016), there are a mass public in the US whose main source of health care if not income is the welfare state but who politically align with agendas to dismantle, privatize or retrench it.

I suggest therefore that policies could just as easily create support for further retrenchments, given that rich democratic welfare states are in a neoliberal era. I suggest that declines in public support might be expected in response to retrenchment. First of all, concrete retrenchments to the generosity of social policies in particular pensions and unemployment took place across the institutional spectrum (Bridgen, 2019; Bridgen and Meyer, 2014; Scruggs, 2006), something I discuss further in the following section. Many scholars ascribe these retrenchments to myriad factors independent of public opinion, such as global developments in trade, aging societies, currency floating, mass automation and increasing popularity of neoliberalism as a policymaking idea (Evans and Sewell Jr, 2013; Huber and Stephens, 2001). Thus, for mostly economic and demographic reasons, policymakers assumed they had 'no choice' but retrenchment (Breznau and Hommerich; van Kersbergen et al., 2014). The result is that most workers retiring on a basic pension into the 2000s are predicted to be worse off economically than their parents in most of these societies (OECD, 2017a).

Given that retrenchment is not popular with the public, it must be that eventually they adjust their "absolute preferences" for new levels of social policy (in Soroka and Wlezien's terms), leading to a lower baseline of public opinion. If they did not do so, there should be mass public unrest due to the gap between the retrenched policies and their preferences, but this is marginally the case. The 
fact is that it takes many years before the material consequences of retrenchments come into force, so the short-term self-undermining feedback of policies gives way over time as social security declines and the public are re-commodified; forced to compete more in the market for their welfare than before (OECD, 2017a). As this takes place, they should adjust expectations downward consistent with the cuts, consistent with competition for increasingly scare welfare resources, and conditioned by politicians and the media discussing the imminent need for cuts (Giger, 2012; Giger and Nelson, 2013; Béland, 2007; Hacker et al., 2015; Schumacher, 2013; Barnes and Hicks 2018). It is likely the public develop norms of welfare competitiveness and become less willing to socially share riskburdens (Breen, 1997). It is also very likely that immigration is a catalyst in these processes that was not as strong in the 1980s and 1990s (Bay and Pedersen, 2006; Burgoon and Rooduijn, 2020). After retrenchments forcibly take place from above the policies become self-reinforcing and potentially decelerating in their effect on public opinion - the returns would now be "increasing" the retrenchments.

Therefore, the "returns" part of Pierson's theory may be as relevant as ever, just "increasing" retrenchment rather than expansion. Pierson suggests that there are turning points in institutional trajectories, and after such events the "returns" to public opinion continue albeit on a new course (Pierson 2004; Pierson 1994, p. 16). Therefore, I suggest that there are new lock-in effects of public opinion after retrenchment course corrections. If these corrections are a turning point, then it is likely the public will begin to favor a stagnant or decreasing institutional path leading to a new equilibrium; a key argument of Pierson's but with the entire system moving in a different direction in a selfreinforcing retrenchment feedback.

Figure 1 presents a heuristic picture of general long-term feedback in theoretical stages. Using the language of Busemeyer et al. (2019), the 'Golden Age' is one of great expansion and accelerating feedback where new policies and their new post-war expansions indicated by the thick green arrow, leads the public increasingly to want more, and policymakers are motivated to give it to them, this is especially a story of an expanding franchise. The 'Silver Age' is a combination of 
neoliberal ideology and economic and demographic changes. The grey arrows behind the blue arrow are reminders that in different regimes and trajectories this phase might be more or less acute in stagnation. As policy retrenches or stagnates, it can no longer produce an accelerating effect. Even if the public at first want more, policymakers do not offer expansions, moreover some of the complexities of each policy do not just produce short-term self-undermining feedback - the relative preference change observed by Soroka and Wlezien (2010) - indicated by undulations in the dotted line representing public opinion, but produce true underlying public opinion changes in absolute preferences - what is unobserved but implied by Soroka and Wlezien's model - noted by an arching of the overall dotted line trajectory across each period. 
Figure 1. Theoretical General Feedback of Public Opinion and the Welfare State

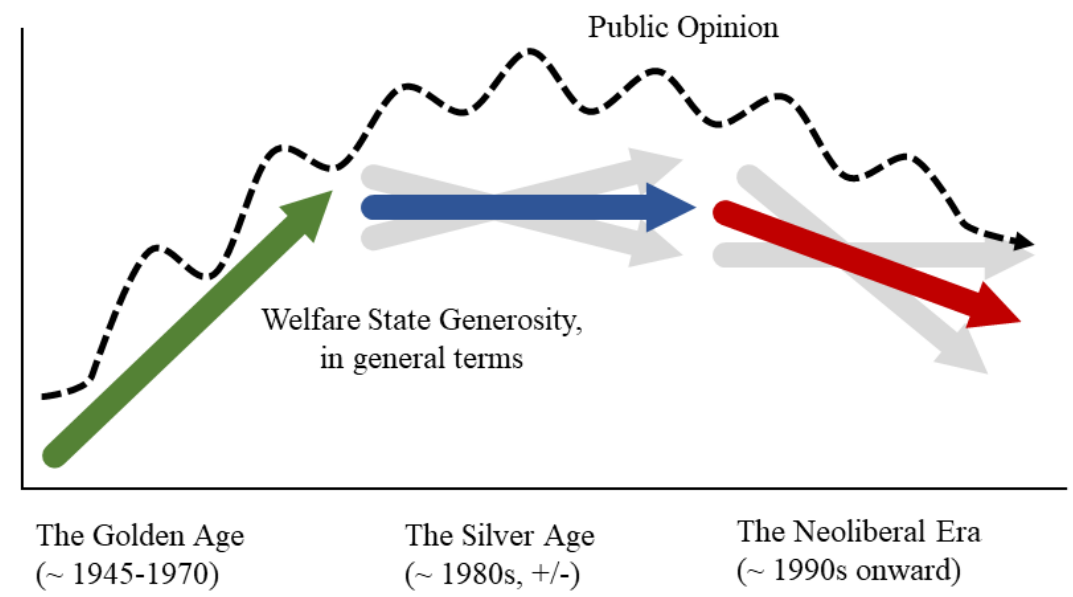




\section{MORE ON RETRENCHMENT}

The social policy literature perpetually debates retrenchment in advanced welfare states (Alm et al., 2020; Böheim and Leoni, 2018; Stephens 2015) therefore more details are warranted here. The empirical side of this debate often uses social spending to measure welfare state 'size'. This indicator suggests the welfare state continued to increase provisions into the 2000s in most countries, but it masks demographic shifts in aging and economic trends that lead to increases without policy changes (Green-Pedersen, 2004). Replacement rates are another option capturing legally defined benefits that individuals and their families actually receive (Scruggs and Allan, 2006). Replacement rate data suggest there was a peak in pensions, work-injury, unemployment and work-related sickness benefits in the late 1970s and early 1980s and then stagnation and decline up to the turn of the millennium (Korpi, 2003). Figure 2 (see Online Appendix ${ }^{1}$ ) demonstrates this for pensions using the Social Insurance Entitlements Dataset (Nelson et al., 2020). From 1930 to 1980 a standard worker couple and the average worker saw rates increase from around $20 \%$ and $15 \%$ respectively to $60 \%$ and $35 \%$ in 17 rich democracies. Thereafter, the rates declined by about 3-5\% and became more 'varied'.

Replacement rates have their own empirical pitfalls. They do no capture changes in labor market policies that require individuals to work in jobs below their skills (Schwander and Häusermann, 2013). Also, changes to eligibility criteria reduce the number of current and future beneficiaries without replacement rate change, a form of 'hidden' retrenchment (van Kersbergen et al., 2014). Wage stagnation and decline also produces lower pensions without a change to replacement rates (Thelen, 2014).

Figure 3, reports adjusted OECD social spending combined with Fraser Institute's indices on government consumption since $1990^{2}$. It demonstrates that after adjusting for old-age-populationratio and unemployment rates there is a downward welfare state trend. I offer this metric here because it will be a key variable in the proceeding analyses, and because it combines a relative

\footnotetext{
${ }^{1}$ https://osf.io/r3vj5/?view_only=a061ff7b00374f24882248cb2037ddbe

${ }^{2}$ Countries in Figure 1:AUS,AUT,CAN,DNK,FIN,FRA,DEU,IRE,ITA,JPN,NET,NZL,NOR, SWE,CHZ,GBR,US; Figure 2 includes these 17 plus PRT,ESP.
} 
measure of spending adjusting for economic and demographic demands, and then standardizes and averages this with scoring from a neoliberal think tank on the openness of the economy (i.e., how much Adam Smith would approve of the level of government economic intervention). I do not offer the measure as a solution to the measurement of general social policy problem, but its neoliberal slant and corrected values offer some improvements. 
Figure 3. The Relative Size of the Welfare State in 19 Countries, 1990-2016 ${ }^{3}$

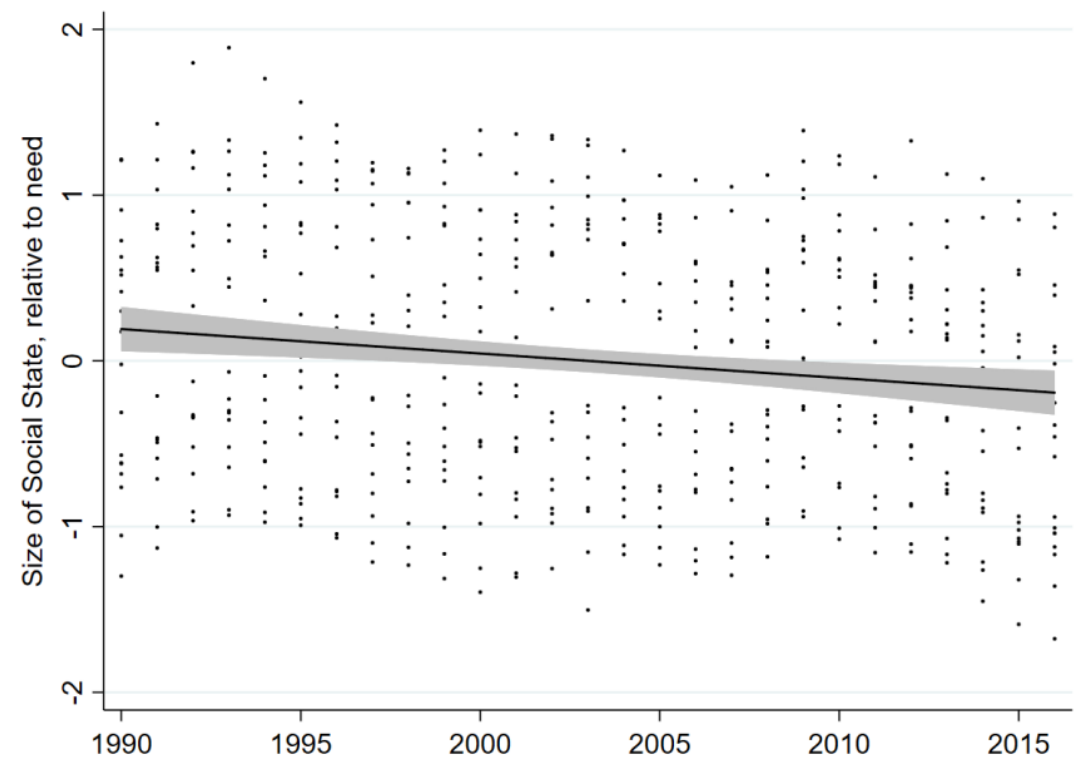

${ }^{3}$ Adjusted for percent of the population over 64 and unemployment rate. 
The average trend masks the varied nature of social policy trajectories across countries since the 1970s (see also Armingeon et al., 2016; Korpi, 2003; Lee et al., 2017). None the less, the general evidence from spending (and government consumption) and replacement rates is that retrenchment took place on average since the 1980s-90s - the 'Neoliberal Era' stylized in Figure 2. Therefore, it is questionable if public opinion has been able to prevent (worse) retrenchment the longer that neoliberal policies are in place.

\section{Bi-DiRECTIONAL FEEDBACK}

Busemeyer et al (2019) provide evidence for their various categories of feedback as derived from the literature, using a pseudo-panel regression approach where certain groups are constructed and the impact of policies on these groups investigated over time using various lags of the policy to predict the group-level preferences. This is in line with Busemeyer et al's definition of policy feedback, "which can be broadly defined as the effect of existing policies and institutions on individual-level attitudes and preferences" (2019, p. 8). This is the state of the art in feedback research, but it is a one-sided view of feedback. It ignores the other direction, where aggregate-level attitudes and preferences (public opinion) shape policies and institutions. There are many studies employing a uni-directional analysis, and some even explicitly refer to the endogeneity problem, or

the fact that feedback runs in both directions (Schakel et al., 2020), but they are all potentially biased when only investigating one direction of effects. The logic is simple, if current policy is a response to recent opinion, then the impact of current policy on future opinion is shaped by previous opinion. Opinion (public preferences) over the long-term is also path dependent, albeit with more variation and short-term feedbacks interwoven. This is why several scholars are able to delineate consistent levels of policy preferences by regime or institutional types (Breznau, 2010; Jæger, 2006; Larsen, 2008; Mehrtens III, 2004; Wendt et al., 2011). The public are a similar group of people under similar policy preference shaping conditions over time in each society - they are endogenous to themselves. 
There is a burgeoning literature using sophisticated methods to try and recover parts of this theoretically bi-directional feedback between opinion and policy (Breznau, 2017; Hakhverdian, 2012; Jones and Baumgartner, 2004; May and Jochim, 2013; Papadakis, 1992; Pierson, 1993; Soroka and Wlezien, 2010). Some demonstrate that opinion and spending respond dynamically or thermostatically, always moving towards absolute preferences (Caughey and Warshaw, 2018; Soroka and Wlezien, 2010; Stimson et al., 1995). Others show public opinion responding to policies, or lack of desired policy changes (Herbst, 2011; Pierson, 1994). Policies determine the distribution of resources (Kenworthy, 1999) and the bureaucratic experiences of individuals (Rothstein, 1998), both shaping public opinion (Lerman and McCabe, 2017). Opinion-policy is a feedback loop of multiple opinions and policies interacting dynamically over time. Presumably feedback loops are at equilibrium, otherwise the opinion-policy systems should become unstable and lead to collapse (i.e., public revolution or institutional breakdown).

\section{TESTING Bi-DiRECTIONAL FEEDBACK}

The ideal research design would have time-series data, clearly specified causal models, reliable measures of all variables and hundreds of cases for comparison. Macro-comparative opinionpolicy research meets few if any of these ideals.

\section{Vibrant theory, no time-series data}

Within-country time-series analysis teaches policy scholars a great deal about opinion-policy responsiveness (Jennings and John, 2009; Jones and Baumgartner, 2005; McCall and Kenworthy, 2009; Soroka and Wlezien, 2005a, 2005b; Wlezien, 1995; Baumgartner et al., 2009), the nature of which may vary by domain (Wlezien, 2004) and the strength or valence of opinion (Jones and Baumgartner, 2004; Judd and Krosnick, 1989). In these mostly single-country studies, results support bi-directional feedback. Unfortunately, cross-nationally comparative time-series data are not available, making a more comprehensive test a challenge. Furthermore, bi-directional feedback is 
negative in the short term, but theoretically positive over the long term creating a potential for confounding in any given model. Figure 3 presents theoretical opinion $(O)$ and policy $(P)$ dynamics over time ( $\mathrm{t}$ ), presumably net of other processes and divided by uni-directional and bi-directional types of feedback. 
Figure 3. Generalized Diagrams of Opinion Feedback and Policy Feedback as a System

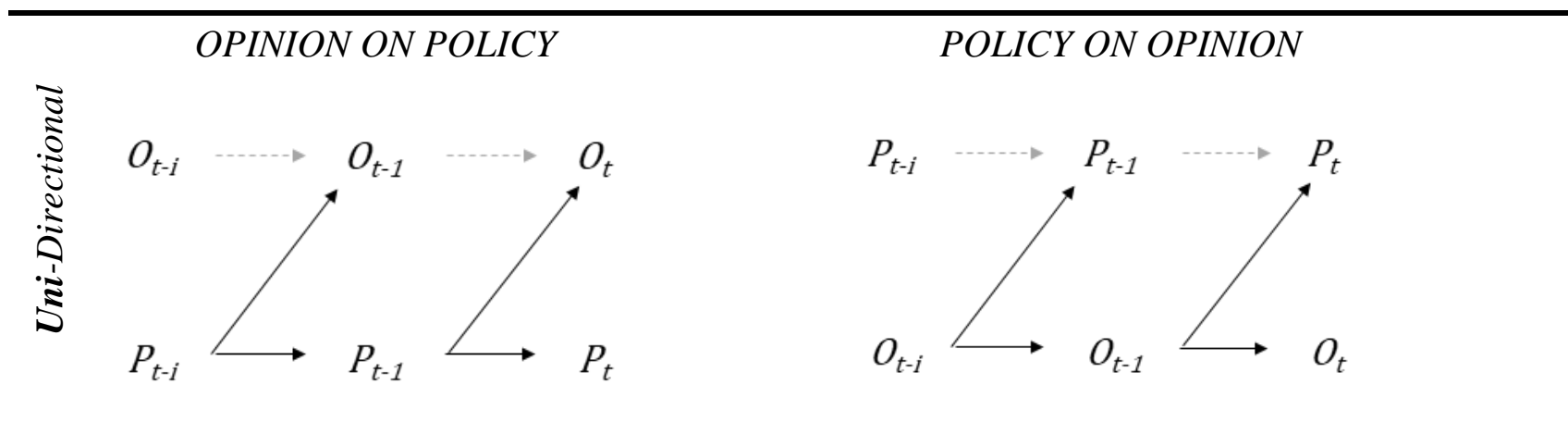

PATH DEPENDENCIES

SELF-REINFORCING ${ }^{4}$
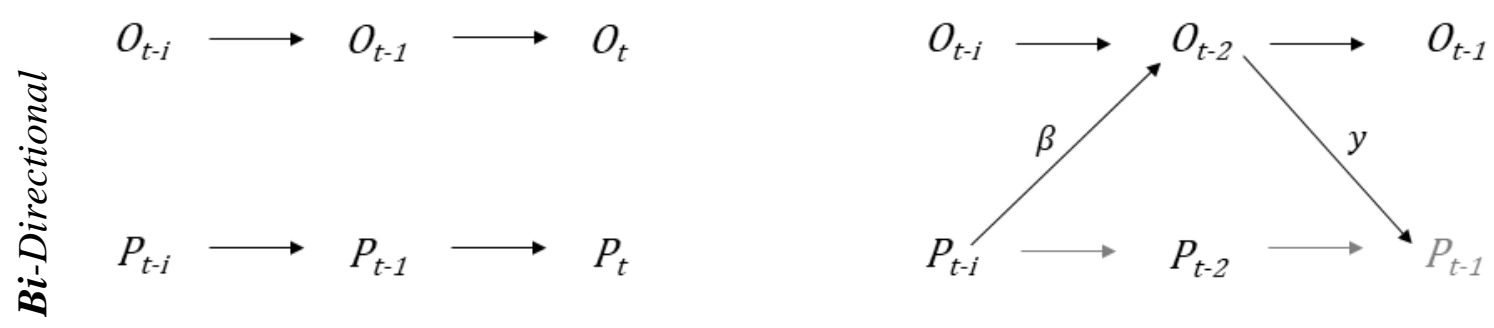

Note: $\beta$ is positive and $y$ is positive

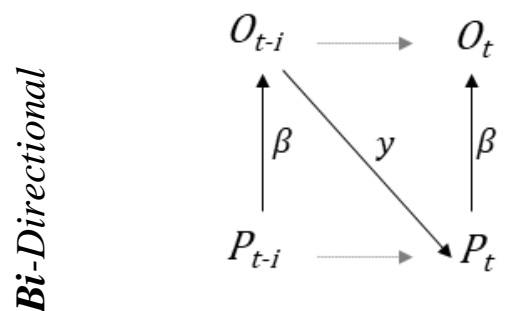

Note: $\beta$ is negative and $y$ is positive

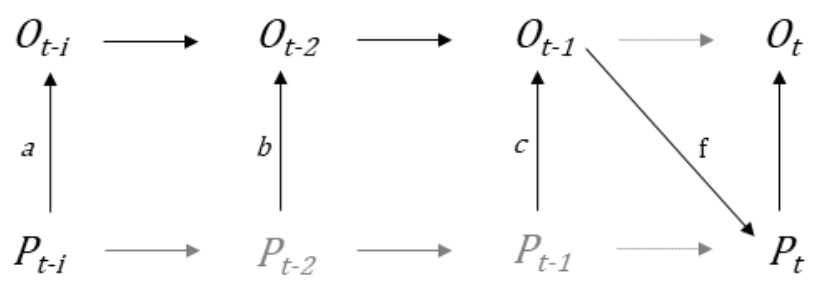

Note: $a \leq b \leq c$; $f$ is a "punctuation"
SIMULTANEITY

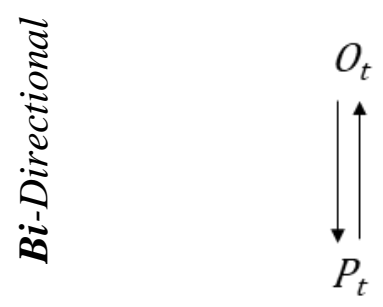

ALL POSSIBLE PATHS

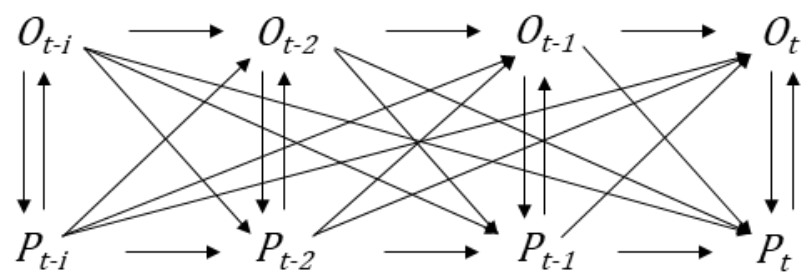

${ }^{4}$ Or "accelerating" depending on the ratio of $\beta$ to $y$ 
OPINION ON POLICY and POLICY ON OPINION models in the top row characterize most of the opinion-policy feedback research. Again, I presume that "feedback" also refers to how opinion shapes policy in addition to how policy shapes opinion. These top row models therefore, potentially suffer from an omitted feedback effect bias demonstrated by the grey dotted arrows, because regression one on the other without considering that the other was previously caused by the one, and the one is not independent of itself over time is a missspecification. Turning to potentials for bidirectional models: PATH DEPENDENCIES models opinion and policy as reinforcing themselves but without more information it implies nil opinion-policy feedback. SELF-REINFORCING (graphically identical with Pierson's increasing returns concept) models $\beta$ as a positive effect of $P$ on $O$, and $y$ as a positive effect of $O$ on $P$, both taking place over time. SELF-UNDERMINING is where $\beta$ is negative in the short-term, but leads to a positive response $y$, and explains equilibrium between opinion and policy (graphically identical to Soroka and Wlezien's thermostatic model). PUNCTUATIONS are moments of sudden feedback. For example, opinion 'builds up' over time when there are absolute public preferences for a policy change that does not happen. The public become increasingly frustrated as time passes without policy change; i.e., $a \leq b \leq c$. Eventually, public opinion is overwhelming or the right opportunity presents itself (Cairney and Jones, 2016), and suddenly there is a shift, i.e., punctuation. This is also a form of self-undermining feedback of policy over time.

The strange bedfellow in Figure 3 is SIMULTANEITY which indicates simultaneously occurring causal effects between opinion and policy. Strict causal inference asserts this is impossible; that time must elapse in order for something to cause something (Pearl, 2009). However, I argue that simultaneous effects are what researchers observe in one year units of analysis. Within a year several causal effects run in both directions. In the ALL POSSIBLE PATHS diagram, the reader can imagine $t$ as weeks or months within a year. But even if it were yearly observations, the ALL POSSIBLE PATHS mode is under-identified and cannot produce any statistical effect parameters. Nonetheless it suggests theoretically the reality of myriad effects overlapping in time with various lengths of lags that should produce an opinion-policy system. These sub-annual processes are unobserved when public opinion 
consists of a year unit. Instead, researchers observe an amalgamation of opinion-on-policy and policy-on-opinion: two total feedback effects for the entire year (or survey period).

Thus, a new strategy is necessary where the timing of events is inferred but not observed. If the events are frequent and have causal effects running in both directions, the SIMULTINEITY model may prove quite accurate empirically despite its coarse level of observation. SIMULTINEITY is a compromise between what is probably the true data-generating model (occurring at both sub- and cross-yearly time points), and what is actually observable in empirical reality (the period captured in each survey wave).

SIMULTINEITY is the only possible choice for modeling bi-directional opinion-policy feedback at the macro-comparative level out of the models shown in Figure 3. This puts a large burden on this particular model. None the less, logic suggests that if there is positive feedback occurring constantly across policies and domains, and if this feedback produces equilibrium, then I should be able to see the feedback in cross-sectional data, a general if not total effect based on all of Busemeyer et al.'s (2019) various feedback categories. Although the SIMULTINEITY model will capture all effect components of the system at once, it still can offer a picture of the very macro and abstract system of the social policy and public opinion, if one exists. That is, so long as I have enough cross-sections. This requires strong assumptions, but these may not be any stronger than the widely accepted assumptions of normally distributed residuals in ordinary least squares regression, or the assumptions that there are no unobserved confounding or observed colliding variables in any model. Taking these assumptions for granted for the time being, the problem finally becomes an empirical one. 
General long-term feedback should produce equilibrium and simultaneity. Therefore, it should outweigh the shorter term and domain-specific fluctuations of opinion and policy. Therefore, I hypothesize that over long periods of time:

\section{H1: the simultaneous coefficients of opinion and policy on each other are positive \\ $\mathrm{H} 2$ : the simultaneous coefficient of opinion on policy is nil \\ H3: the simultaneous coefficients of opinion and policy on each other are both nil}

Given that $\mathrm{H} 1$ predicts the simultaneous existence of two effects, there is no null-hypothesis. Forcing one effect to be zero has implications to the other effect.

In case policy impacts public opinion, a theory of positive returns suggests the public absorbs the benefits or harms of a policy change and public opinion reacts to demand more or less of that policy. However, very few policies have an immediate social welfare impact on individuals, they take years to implement, for example the Hartz Reforms took place over eight years and the Affordable Care Act had effects only four years after being passed as law. Policies sometime lead to negative feedback (Weaver, 2010). The welfare state and concomitant laws and bureaucracies is more complex (Béland and Schlager, 2019). The public has exceeding difficulty understanding their own social insurance systems and social welfare systems as do politicians and scholars (Jensen et al., 2019). Moreover, the science of public opinion and persuasion is well-developed and provides tools for parties and special interest groups to deploy in order to shift discourses in the public sphere essentially hiding or 're-branding retrenchments'. For these reasons, I take the primary competing hypothesis H2: that opinion demonstrates no effect on policy.

Although theoretically unlikely, I offer a nil hypothesis. In policymaking, a variety of interests come together to develop and implement a policy. Patashnik and Zelizer (2013) suggest that the intricacies of this process may lead to "incomplete displacement" and "inadequate state capacity" to sustain the policy's intended changes for individual recipients (see also Soss and Schram, 2007). 
Without effective material or welfare changes, public opinion is unlikely to change, as argued in the theory of increasing returns (Pierson, 1994). Therefore, it is possible that Pierson's increasing returns really only applied to the historical rise of welfare state policies, and these now mature and institutionalized polices no longer bring about sustainable opinion change (Raven et al., 2011) or only lead to opinion changes in subsets of the public (Bendz, 2015). Alternatively, policy may be the decisive factor in the opinion-policy dynamic. It may drive the entire system and constrain or enable its own future via policymakers despite the preferences of the public (Morgan and Campbell, 2011). Thus, I propose H3: effects between opinion and policy are mathematically zero, not just insignificant. This is crucial counter-hypothesis, because it undermines a theory of positive returns.

\section{Populating a simultaneous feedback model}

Data selection is easy, for better or worse. The International Social Survey Program (ISSP) 'Role of Government' Module is the only source for a battery of questions on the welfare state and recurring comparative samples. The first wave was 1985 with only 5 countries, therefore I use 1990 onwards including 19 countries with roughly three observations each through 2016 . As an indicator for public support of a social welfare state, I use a battery of 7 questions on how much the respondent agrees or not that it is the role of government to provide for health, old age, unemployment, income distribution, employment, price controls and industrial decline. Other research suggests these 7 items are metric invariant and suitable to construct a reflective indicator of public opinion (Breznau 2019). Again this is a macro-level undertaking and it is unlikely that any simple, single opinion can recover a position toward all of the complexities of the welfare state at once. Descriptive statistics available in Table 1 in the Online Appendix.

As discussed with Figures 1 and 2, social spending as a measure of social policy is problematic because it can change dramatically without any policy changes (Green-Pedersen, 2004). Harmonized data across several countries that measures the size or scope of the welfare state beyond 
spending does not exist ${ }^{5}$. As an alternative I propose using policy coding from an unlikely source. The Fraser Institute is an organization without partisan affiliation based in Canada whose primary mission is to measure economic freedom as far back as 1950 . The Institute collects data in five areas: Size of Government, the Legal System and Security of Property Rights, Sound Money, Freedom to Trade Internationally, and Regulation. They are staunchly against social welfare states as impediments to economic freedom, thus their data should 'punish' any taxation, transfers, spending and regulations.

The economic freedom rankings of the rich democratic welfare states of the world are high, ranking between 7 and 8 out of 10, but they are not the highest; this is reserved for states with minimal social policy intervention into socio-economic affairs such as Hong Kong and Singapore. Nonetheless, the large welfare states of Europe and Scandinavia rank slightly lower than the liberal settings of New Zealand, the United States and United Kingdom for example. These rankings diverge even more when focusing on just two areas: Size of Government and Regulation. The Fraser data has two indicators for Size of Government: consumption, and subsidies and transfers. I combine these with OECD Social Expenditures variable and generate an index that roughly measures the size of the social welfare state (see Table 2 in Online Appendix). For Regulation, the Fraser Institute has 4 consistent measures from 1990 through 2016 of wage setting, job dismissal protections, institutionalized collective bargaining and labor protections such as working hours. I also construct an index of these highly correlated measures of the extent of labor market policy. Due to missing data I am forced to drop wage setting in calculation of the final scale.

If bi-directional feedback continue after the 'increasing' phase of welfare states, then opinion should eventually track the downward trend after the 1980s shown in Figures 1 and 2, i.e., opinion and policy should positively correlate. Whether this correlation indicates returns depends on adjusting for the range of other causal pathways to opinion and policy working at different micro, meso and macro-levels. Weaker economies encourage public opinion to be more supportive of social

\footnotetext{
${ }^{5}$ Comparative Welfare Entitlements Database measures replacement rates but only to 2010 .
} 
policy out of need, thus lower levels of GDP per capita and higher rates of unemployment should predict higher support for social policy (Blekesaune, 2007; Wilensky, 1975). Where there are more sick, unemployed and pension recipients, there are higher levels of social spending. However, GDP and unemployment are highly correlated due to the 'healthiness' of the economy. Therefore, unemployment should only be used as a partial correlation after adjusting for GDP. As pensioners are also at a point in the life course that has higher medical costs, the percentage of the population aged 65 and older is a critical predictor variable as it helps adjust for the need of the welfare state as shown in Figure 2 (Pampel and Williamson, 1985). Finally, the percentage of the total legislative seats held by right parties as opposed to left or center parties should reflect less social welfare policy (and spending), but also lead to less provision of welfare through agenda setting (Huber et al., 1993; Jensen, 2011). The left-right distinction is crude and has lost its clear connection with policy outcomes in modern times, nonetheless for comparison across very diverse political systems this offers some kind of control variable. Of course, parties should also influence opinion (Leeper and Slothuus, 2014). To construct these indicators, I use data from the World Bank found in the Quality of Government (QoG) database (Teorell et al., 2017).

Important caveats: A measure of aged is presumably not correlated with public opinion given that pensioners are often surprisingly opposed to government social policy size and scope despite being major recipients. Moreover, individual attitudes can change dramatically over the life course. Therefore, I leave out the variable aged from any prediction of public opinion; not that it is not a cause, but that it has some kind of non-linear relationship that goes beyond the scope of this research to attempt to recover. This is empirically justifiable as initial models demonstrate that its effect is close to zero and does not disturb the other effects, but its removal offers a gain of one precious model parameter. 
Testing bi-directional feedback

Looking at the public opinion measure in Figure 4 reveals a decreasing trend over time in the 19 rich welfare states available in the ISSP. 
Figure 4. Public Opinion across Four ISSP 'Role of Government' Waves

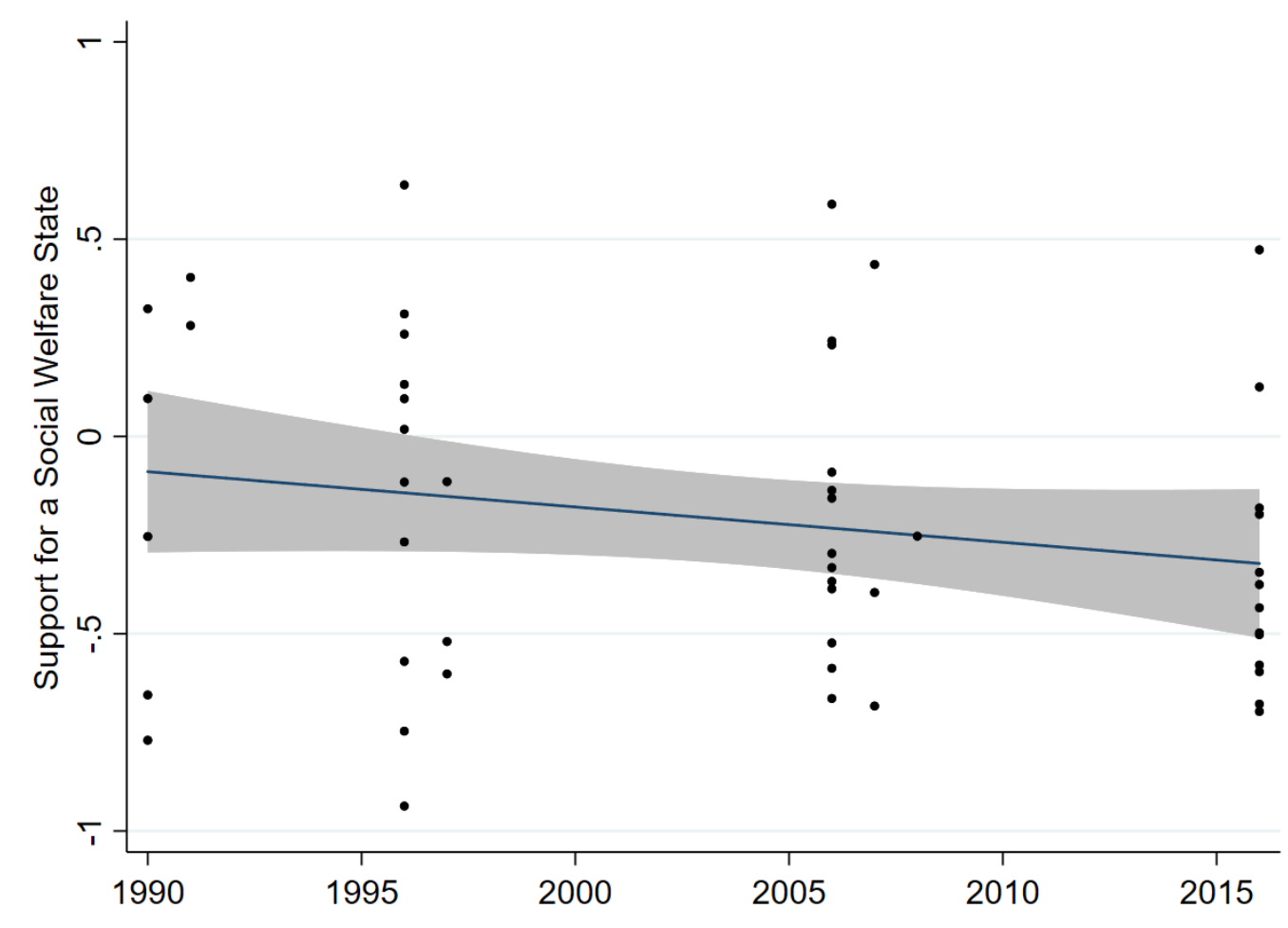


The similar downward trends in Figures 2 and 4 might be happenstance (H3), or part of a theoretically causal feedback process (H1). To test this, I employ simultaneous feedback models. An obstacle to testing for a reciprocal relationship of opinion and policy, is that they have only one observable empirical association. They have one covariance, whereas theory suggests two different effects running between them. Thus, estimation of SIMULTINEITY in Figure 3 is not possible with these two variables alone. The model is underidentified (SEM identification rules, e.g., Kline, 2016). I need at least two variables that meet exogeneity requirements to achieve identification, one for opinion and one for policy.

Some researchers point toward institutions as exogenous to opinion but a cause of policy, with a particular eye on veto powers (Gabel and Scheve, 2007; Matsusaka, 2005; Poterba, 1995). The more veto opportunities available to competing interests across parties or levels of governance, the less likely social policies become law (Crepaz and Lijphart, 1995). In particular, competitive veto points lead to lesser social policy provisions (Crepaz and Moser, 2004). The design of political institutions harks back to nation-state-foundational laws and procedures, they should not have the possibility to impact public opinion in modern times, except for indirectly through policy or the nature of partisan competition.

At least one scholar argued for female labor force participation (female $L F P$ ) as exogenous to policy. It should cause opinion through working women (and men for that matter) having more market-oriented or liberal-market values (Breznau 2017). Thus, more working women means greater opposition to social welfare. Although women's first mass movements into the labor force generated new and expanding forms of social policy, given that women were previously disadvantaged or excluded from traditional pension systems (Huber and Stephens, 2000), this impact should have run its course by the 1990s. Thereafter, a gendered impact on policy should only come through women's public opinion, i.e., indirectly. This is easily observable in the policy landscape across countries. For example, Sweden and the US have radically different social policies but similarly high levels of working women. Although somewhat contentious, I take these as the best available instruments for 
identification of the simultaneous feedback model. I measure collective veto points with 4-items used by others (Breznau, 2017; Crepaz and Lijphart, 1995) and female LFP via the World Development Indicators in the Quality of Government data (Teorell et al., 2017).

I populate the simultaneous feedback models with these measures and use maximum likelihood estimation. The convergence derives from two equations in simultaneity, and multiple solutions are possible that minimize covariance residuals. I seek evidence to select one over others. M0 is the first model and it acts as a justidentified baseline. It does not test anything but sets chisquare/degrees-of-freedom for comparison. In M1, I test the bi-directional feedback predictions of $\mathrm{H} 1$ for the size of the social state. Bi-directional feedback suggests opinion-policy effects should be positive and similarly sized. Based on previous research using simultaneous feedback, I expect small to moderate effect sizes (Breznau 2017; Soroka and Wlezien 2010). Therefore, I fix both effects to 0.15 in standardized terms.

Next, M2 tests for a nil effect of opinion on policy (H2), and M3 tests for a nil/nil effect of both opinion and policy on each (H3). I compare the models to M0 using equal fit tests. When models have a lower p-value approaching zero $(<0.05)$, they fit significantly worse than M0 and should be cast out. Next, I compare M1-M3 to each other. Again, models that fit worse should be cast out, but if $p$-values are larger $(p>0.05)$ it indicates the models fit similarly to the data. In such cases, logic prefers the model with fewer degrees of model-freedom because of the parsimony principle (Occam's logic) where the simpler model is always better, all else equal. Next, I rerun the four models with extent of labor market policy as the DV, (M10-M14). Finally, I rerun all models with the residual opinion-policy error fixed at zero as a robustness test (see Online Appendix Table 4).

I present results here as path diagrams with standardized coefficients for easier visual interpretation. The fit tests are in Online Appendix Table 3. All p-values except M3 suggest that fit is not significantly worse than M0 suggesting that only M3 should be immediately eliminated. For both policy variables, the bi-directional feedback models (M1 and M11) show no significant difference in 
fit from the nil opinion models (M2 and M12). This favors the bi-directional feedback models because they have one degree of freedom less. Finally, the M3 and M13 nil opinion and nil policy effects models fit worse with p-values of 0.000 (M3) and 0.093 (M13). The results for M13 are questionable. They are towards zero suggesting they are significantly worse, but only barely. By some standards researchers might conclude that M11 and M13 are equal. Here the looming small-N of 51 suggests that a strict cutoff of 0.05 or lower might be too strict.

The RMSEA, AIC and BIC values generally favor H1, but a questionable result is the RMSEA and CFI in models M11-M13. The RMSEA is 0.000 and CFI is 1.000 in all except M13. This suggests the models behave more justidentified than overidentified. Although they are overidentified in parameters, the statistical properties may not be 'strong enough' to produce useful test results (Hayduk 2014). This is also evident in the lack of effect of collective veto points on labor market policy, although it is expected, making this a potentially problematic instrument.

Figure 5 presents M1, simultaneous feedback between public opinion and size of the social state, and Figure 6 (Online Appendix) presents M11, simultaneous feedback between public opinion and the extent of labor market policy. Solid arrows represent regression coefficients with sizes that warrant attention while the dotted greyish arrows have effects near zero or with confidence intervals that are so wide they should not be trusted. Dashed two-headed arrows are residual opinion-policy covariances. 
Figure 5. Simultaneous Feedback Model Testing Bi-directional feedback in Size of the Social State

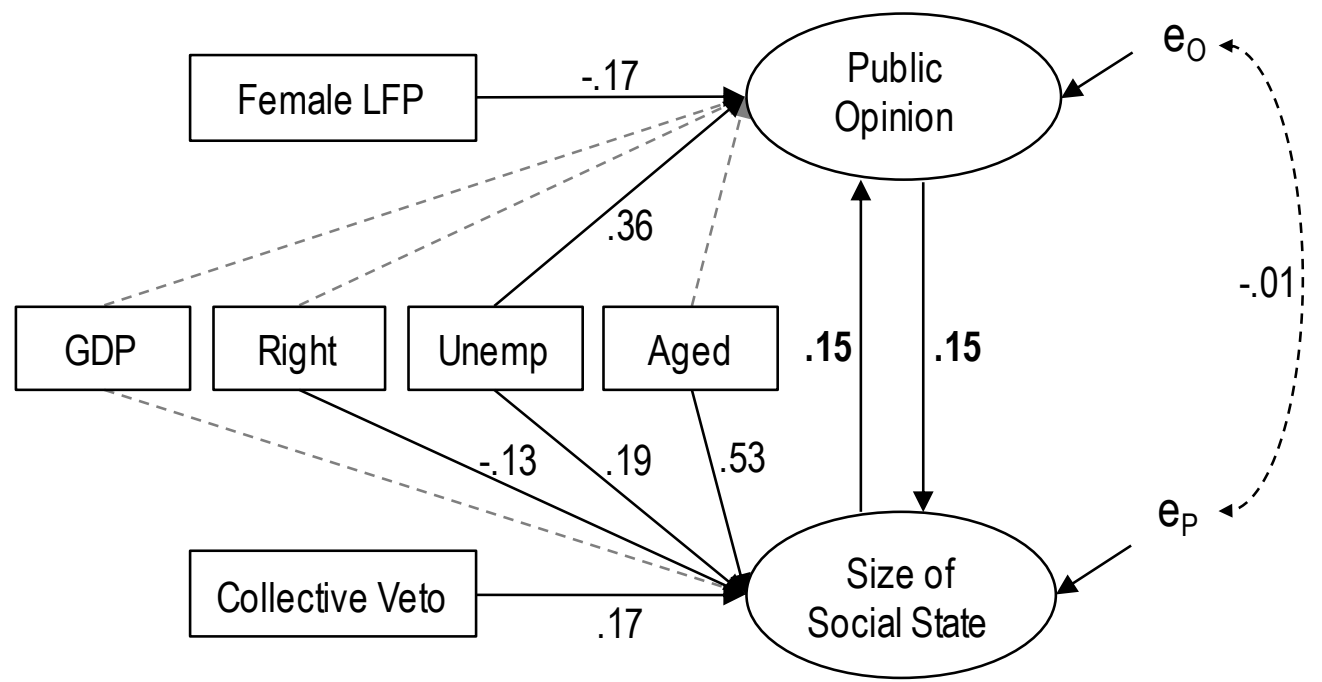




\section{DISCUSSION}

Using representative surveys, and measuring the size of the welfare state and extent of labor market policy among rich democratic societies, I tested a positive relationship of public opinion and social policy. The evidence favors bi-directional feedback (H1) over one possible 'null' hypothesis that opinion does not affect policy (H2) and a 'nil' hypothesis that both effects of opinion and policy are zero (H3). The data suggest moderately sized positive effects of opinion and policy on each other across time and space is a reasonable data-generating assumption; as long as the models are correctly specified. The results support bi-directional feedback as a useful general description of the relationship of public opinion and social policy between 1990 and 2016 across 19 rich democratic welfare states.

The effects of key independent variables are sized and signed in ways that previous welfare state research anticipates lending support to my simultaneous feedback models. Namely, unemployment and GDP have moderately sized positive effects on public opinion, this should reflect that an unhealthy labor market and economy produce greater support for government intervention. GDP does not predict the size of the welfare state or extent of labor market policy here despite functionalist theory predicting countries with more wealth should spend more. This is perhaps not surprising because all these countries are rich. The GDP differences are tiny compared to variance in institutional designs (Esping-Andersen, 1989; Pierson, 2004), for example the lower GDP Mediterranean countries have very large welfare states while the higher GDP United States and Japan have smaller welfare states.

Right party control of government predicts smaller social states and less extensive labor market policy, in line with expectations. However, right party power does not predict public opinion. This suggests that although right parties are interested in smaller social states, the public may react thermostatically to them when they are in power, i.e., negative corrections in opposition to their policy positions. This means that public opinion captures some of the partisan effect on policy and policy captures some of the partisan effect on opinion leading to suppression of the effect 
statistically. If more degrees of model freedom or cases were available, parties should also be seen as an endogenous variable, but this is beyond what is testable here.

The model I presented assumes there is an underlying equilibrium to opinion and policy as a system. The negative residual correlation shown by the dotted lines in both Figures 5 and 6 suggests that the unobserved variance of opinion and policy not captured in the model pushes opinion and policy 'toward' each other. This means that from a very macro-perspective, opinion and policy behave like magnets. When one error is higher the other is lower, thus keeping the system on course. However, this assumption of equilibrium is theoretical more than empirical. Only theory can define what it means for opinion and policy to be at equilibrium; something Pierson elaborates in his discussions of path dependency.

Results here are very speculative. A model of simultaneous feedback is non-recursive. The effect of opinion on policy depends of the effect of policy on opinion and vice-versa. Neither is identified mathematically without the other. This puts a big burden on theory and model specification, rather than reliance on multivariate statistics, to identify unknown effects. What is also missing in these models is short term negative feedback. I assume there are many punctuations and variances that occur within and between year units (Jones and Baumgartner, 2012), but yearly survey data do not identify these micro-processes. Finally, the models suffer from standard problems in macro-comparative research (Kenworthy, 2007; Kittel, 2006). Small-N studies lack statistical power, and having an endogenous loop does not improve this.

I urge readers to take the lessons of this paper in the realm of theory before statistics. The simultaneous feedback model is a more accurate portrayal of the theoretical opinion-policy system than a unidirectional regression model. The typical unidirectional model is potentially misspecified because it does not account for reciprocal causality. Unidirectional models might recover a policy feedback effect disguised as a positive effect of opinion on policy (discussions in Soroka and Wlezien, 2010). I am hopeful that future scholars consider this carefully before running more unidirectional models of either opinion on policy or policy on opinion. Taking the endogeneity 
between opinion and policy over time seriously requires innovative research. For example, one exceptional study from Soroka and Wlezien (2012) attempted to fit 'time-series' approaches into cross-sectional data using a model to test that institutions, for example federalism, constrain the effects of policy on opinion. Along these lines, I believe macro-comparative researchers need to rethink the way they measure and identify opinion-policy effects; this would move their work forward in a similar way that within-country time-series analysis innovations did in the past decades (Hakhverdian, 2012; Jennings and John, 2009; Wlezien, 1995).

The theory of bi-directional feedback presented here relies on the assumption of institutional turning points, or branches, that shifted the growth phase of welfare states into one of stagnation and retrenchment. There are myriad economic and demographic discussions of this phenomenon. I suspect there are even more causes or catalysts that I could elaborate on in this short paper. For example, group dynamics. Mass migration and intergroup conflict may lead 'natives' to be less supportive of social policies when they think these disproportionately benefit 'non-native' groups (Kaufmann 2019; Eger and Breznau, 2017; Schmidt-Catran and Spies, 2016). Therefore, the bidirectional feedback process may require new theoretical components beyond Pierson's increasing returns. Populism, democratic decline and increasing material inequality should not be discounted. I hope this paper sets the theoretical stage for future research on this subject, and helps deliver Pierson's influential increasing returns arguments into theories of welfare states after their 'golden ages'.

Although I tried to capture the key variables in the opinion-policy process I cannot systematically account for history, culture, and context-specific institutional forks that make each society unique (Pierson, 2004). The research herein is at a high level of abstraction. I am investigating broad, macro-generalities. A general positive feedback between opinion and policy does not indicate that at specific times and places the process is always positive, nor does it indicate that the causal mechanisms take place at this macro-level. Whether or not the reader buys the 
methods herein, I humbly assert that these models are better than other that ignore endogeneity, and may be the best we have yet when addressing this topic using comparative survey data. 


\section{REFERENCES}

Alm, Susanne, Kenneth Nelson, and Rense Nieuwenhuis. 2020. "The Diminishing Power of One? Welfare State Retrenchment and Rising Poverty of Single-Adult Households in Sweden 1988-2011." European Sociological Review 36(2):198-217.

Armingeon, Klaus, Kai Guthmann, and David Weisstanner. 2016. "Choosing the Path of Austerity: How Parties and Policy Coalitions Influence Welfare State Retrenchment in Periods of Fiscal Consolidation." West European Politics 39(4):628-47.

Arts, Wil, and John Gelissen. 2002. "Three Worlds of Welfare Capitalism or More? A State-of-theArt Report.” Journal of European Social Policy 12(2):137-158.

Barnes, Lucy, and Timothy Hicks. 2018. "Making Austerity Popular: The Media and Mass Attitudes toward Fiscal Policy." American Journal of Political Science 62(2):340-54.

Baumgartner, Frank R et al. 2009. "Punctuated Equilibrium in Comparative Perspective." American Journal of Political Science 53(3):603-620.

Bay, A.-H., Pedersen, A.W., 2006. The Limits of Social Solidarity: Basic Income, Immigration and the Legitimacy of the Universal Welfare State. Acta Sociol. 49, 419-436. https://doi.org/10.2307/20459958

Béland, Daniel. 2007. "Ideas and Institutional Change in Social Security: Conversion, Layering, and Policy Drift." Social Science Quarterly 88(1):20-38.

Béland, D., Schlager, E., 2019. Varieties of Policy Feedback Research: Looking Backward, Moving Forward. Policy Stud. J. 47, 184-205. https://doi.org/10.1111/psj.12340

Bendz, Anna. 2015. "Paying Attention to Politics: Public Responsiveness and Welfare Policy Change." Policy Studies Journal 43(3):309-332.

Blekesaune, M. 2007. "Economic Conditions and Public Attitudes to Welfare Policies." European Sociological Review 23(3):393-403.

Böheim, René, and Thomas Leoni. 2018. "Sickness and Disability Policies: Reform Paths in OECD Countries between 1990 and 2014." International Journal of Social Welfare 27(2): 168-85.

Breen, R. 1997. "Risk, Recommodification and Stratification." Sociology-the Journal of the British Sociological Association 31(37310):473-489.

Breznau, N., 2010. Economic Equality and Social Welfare: Policy Preferences in Five Nations. Int. J. Public Opin. Res. 22, 458-484. https://doi.org/10.1093/ijpor/edq024

Breznau, Nate. 2017. "Positive Returns and Equilibrium: Simultaneous Feedback Between Public Opinion and Social Policy." Policy Studies Journal 45(4):583-612. . 2018. "Simultaneous Feedback Models with Macro-Comparative Cross-Sectional Data." Methods, Data, Analyses 12(2):265-308.

. 2019. "The Underlying Public Attitude toward Government Responsibility to Intervene in Socio-Economics, Thirty-Years of Evidence from the ISSP.” International Journal of Sociology 49(3):182-203.

Bridgen, P., 2019. The retrenchment of public pension provision in the liberal world of welfare during the age of austerity — and its unexpected reversal, 1980-2017. Soc. Policy Adm. 53, 16-33. https://doi.org/10.1111/spol.12444

Bridgen, P., Meyer, T., 2014. The Liberalisation of the German Social Model: Public-Private Pension Reform in Germany since 2001. J. Soc. Policy 43, 37-68.

Briggs, Asa. 1961. "The Welfare State in Historical Perspective." In The Welfare State Reader, eds. Christopher Pierson and Francis G. Castles. Cambridge: Polity Press (2006),17-29.

Burgoon, B., Rooduijn, M., 2020. 'Immigrationization' of welfare politics? Anti-immigration and welfare attitudes in context. West Eur. Polit. 0, 1-27. https://doi.org/10.1080/01402382.2019.1702297

Busemeyer, M.R., Abrassart, A., Nezi, R., 2019. Beyond Positive and Negative: New Perspectives on Feedback Effects in Public Opinion on the Welfare State. Br. J. Polit. Sci. 1-26. https://doi.org/10.1017/S0007123418000534 
Cairney, Paul, and Michael D Jones. 2016. "Kingdon's Multiple Streams Approach: What Is the Empirical Impact of This Universal Theory?" Policy Studies Journal 44(1):37-58.

Campbell, Andrea Louise. 2012. "Policy Makes Mass Politics." Annual Review of Political Science 15(1):333-351.

Castles, Francis G, and Herbert Obinger. 2008. "Worlds, Families, Regimes: Country Clusters in European and OECD Area Public Policy." West European Politics 31(1):321-344.

Caughey, Devin, and Christopher Warshaw. 2018. "Policy Preferences and Policy Change: Dynamic Responsiveness in the American States, 1936-2014.” American Political Science Review 112(2):249-266.

Crepaz, Markus, and Arend Lijphart. 1995. "Linking and Integrating Corporatism and Consensus Democracy.” British Journal of Political Science 25(24642):281-288.

Crepaz, Markus, and Ann W Moser. 2004. "The Impact of Collective and Competitive Veto Points on Public Expenditures in the Global Age." Comparative Political Studies 37(3):259-285.

Eger, Maureen A, and Nate Breznau. 2017. "Immigration and the Welfare State: A Cross-Regional Analysis of European Welfare Attitudes." International Journal of Comparative Sociology 58(5):440-463.

Esping-Andersen, Gosta. 1989. "The Three Political Economies of The Welfare State." Canadian Review of Sociology/Revue canadienne de sociologie 26(1):10-36.

Evans, Peter, and William H Sewell Jr. 2013. "The Neoliberal Era: Ideology, Policy, and Social Effects." In Social Resilience in the Neo-Liberal Era, eds. Peter A Hall and Michèle Lamont. New York: Cambridge University Press,35-68.

Gabel, Matthew, and Kenneth Scheve. 2007. "Estimating the Effect of Elite Communications on Public Opinion Using Instrumental Variables.” American Journal of Political Science 51(4):1013-1028.

Giger, Nathalie. 2012. "Is Social Policy Retrenchment Unpopular? How Welfare Reforms Affect Government Popularity.” European Sociological Review 28(5):691-700.

Giger, Nathalie, and Moira Nelson. 2013. "The Welfare State or the Economy? Preferences, Constituencies, and Strategies for Retrenchment." European Sociological Review 29(5):1083-1094.

Green-Pedersen, Christoffer. 2004. "The Dependent Variable Problem within the Study of Welfare State Retrenchment: Defining the Problem and Looking for Solutions." Journal of Comparative Policy Analysis: Research and Practice 6(1):3-14.

Hacker, Jacob S. 1998. "The Historical Logic of National Health Insurance: Structure and Sequence in the Development of British, Canadian, and U.S. Medical Policy." Studies in American Political Development 12(01):57-130.

Hacker, Jacob S, Paul Pierson, and Kathleen Thelen. 2015. "Drift and Conversion: Hidden Faces of Institutional Change." In Advances in Comparative-Historical Analysis, Cambridge: Cambridge University Press, 180-208.

Hakhverdian, Armen. 2012. "The Causal Flow between Public Opinion and Policy: Government Responsiveness, Leadership, or Counter Movement?” West European Politics 35(6):13861406.

Herbst, Susan. 2011. "Critical Perspectives on Public Opinion." In The Oxford Handbook of American Public Opinion and the Media, eds. Robert Y Shapiro and Lawrence R Jacobs. Oxford: Oxford University Press,302-314.

Huber, Evelyne, Charles Ragin, and John D Stephens. 1993. "Social Democracy, Christian Democracy, Constitutional Structure, and the Welfare State." The American Journal of Sociology 99(3):711-749.

Huber, Evelyne, and John D Stephens. 2000. "Partisan Governance, Women's Employment, and the Social Democratic Service State.” American Sociological Review 65(3): 323-342. . 2001. Development and Crisis of the Welfare State: Parties and Policies in Global Markets. Chicago: University of Chicago Press. 
Jæger, M.M., 2006. Welfare Regimes and Attitudes Towards Redistribution: The Regime Hypothesis Revisited. Eur. Sociol. Rev. 22, 157-170. https://doi.org/10.1093/esr/jci049

Jennings, Will, and Peter John. 2009. "The Dynamics of Political Attention: Public Opinion and the Queen's Speech in the United Kingdom.” American Journal of Political Science 53(4):838854.

Jensen, Carsten. 2011. "Two Sides of the Same Coin? Left-Wing Governments and Labour Unions as Determinants of Public Spending." Socio-Economic Review 10(2):217-240.

Jensen, Carsten, Georg Wenzelburger, and Reimut Zohlnhöfer. 2019. "Dismantling the Welfare State? After Twenty-Five Years: What Have We Learned and What Should We Learn?" Journal of European Social Policy 29(5):681-91.

Jones, Bryan D, and Frank R Baumgartner. 2004. "Representation and Agenda Setting." Policy Studies Journal 32(1):1-24.

. 2005. The Politics of Attention: How Government Prioritizes Problems. Chicago: University of Chicago Press.

. 2012. "From There to Here: Punctuated Equilibrium to the General Punctuation Thesis to a Theory of Government Information Processing." Policy Studies Journal 40(1):1-20.

Judd, Charles M, and Jon A Krosnick. 1989. “The Structural Bases of Consistency among Political Attitudes: Effects of Political Expertise and Attitude Importance." In Attitude Structure and Function, eds. Anthony R. Pratkanis, Steven J. Breckler, and Anthony G. Greenwald. New York: Psychology Press,99-128.

Kaufmann, Eric. 2019. Whiteshift: Populism, Immigration, and the Future of White Majorities. Abrams.

Kenworthy, Lane. 1999. "Do Social-Welfare Policies Reduce Poverty? A Cross-National Assessment." Social Forces 77(3):1119-1139.

. 2007. "Toward Improved Use of Regression in Macro-Comparative Analysis." Comparative Social Research 24(3):343-350.

van Kersbergen, Kees, Barbara Vis, and Anton Hemerijck. 2014. "The Great Recession and Welfare State Reform: Is Retrenchment Really the Only Game Left in Town?” Social Policy \& Administration 48(7):883-904.

Kittel, Bernhard. 2006. "A Crazy Methodology? On the Limits of Macro-Quantitative Social Science Research.” International Sociology 21(5):647-677.

Kline, Rex B. 2016. Principles and Practice of Structural Equation Modeling. 4th Editio. New York and London: Guilford Press.

Korpi, Walter. 2003. "Welfare State Regress in Western Europe: Politics, Institutions, Globalization, and Europeanization." Annual Review of Sociology 29(1):589-609.

Larsen, C.A., 2008. The Institutional Logic of Welfare Attitudes: How Welfare Regimes Influence Public Support. Comp. Polit. Stud. 41, 145-168. https://doi.org/10.1177/0010414006295234

Lee, Seonghui, Carsten Jensen, Christoph Arndt, and Georg Wenzelburger. 2017. "Risky Business? Welfare State Reforms and Government Support in Britain and Denmark." British Journal of Political Science 50(1):1-20.

Leeper, Thomas J, and Rune Slothuus. 2014. "Political Parties, Motivated Reasoning, and Public Opinion Formation.” Political Psychology 35(S1):129-156.

Lerman, Amy E, and Katherine T McCabe. 2017. "Personal Experience and Public Opinion: A Theory and Test of Conditional Policy Feedback." The Journal of Politics 79(2): 624-641.

Matsusaka, John G. 2005. "The Endogeneity of the Initiative: A Comment on Marschall and Ruhil." State Politics \& Policy Quarterly 5(4):356-363.

Mau, Steffen. 2004. "Welfare Regimes and the Norms of Social Exchange." Current Sociology 52(1):53-74.

May, Peter J, and Ashley E Jochim. 2013. "Policy Regime Perspectives: Policies, Politics, and Governing.” Policy Studies Journal 41(3):426-452. 
McCall, Leslie, and Lane Kenworthy. 2009. “Americans' Social Policy Preferences in the Era of Rising Inequality." Perspectives on Politics 7(3):459-484.

Mehrtens III, F.J., 2004. Three Worlds of Public Opinion? Values, Variation, and the Effect on Social Policy. Int. J. Public Opin. Res. 16, 115-143. https://doi.org/10.1093/ijpor/16.2.115

Morgan, Kimberly J, and Andrea Louise Campbell. 2011. 1 The Delegated Welfare State: Medicare, Markets, and the Governance of Social Policy. New York: Oxford University Press USA.

Obinger, Herbert, Carina Schmitt, and Peter Starke. 2013. "Policy Diffusion and Policy Transfer in Comparative Welfare State Research.” Social Policy \& Administration 47(1):111-29.

OECD. 2017a. Pensions at a Glance 2017. https://www.oecdilibrary.org/content/publication/pension_glance-2017-en. . 2017b. Preventing Ageing Unequally. https://www.oecdilibrary.org/content/publication/9789264279087-en.

van Oorschot, Wim. 2010. "Public Perceptions of the Economic, Moral, Social and Migration Consequences of the Welfare State: An Empirical Analysis of Welfare State Legitimacy." Journal of European Social Policy 20(1):19-31.

Pampel, F C, and J B Williamson. 1985. "Age Structure, Politics, and Cross-National Patterns of Public Pension Expenditures.” American Sociological Review 50(6139):782-799.

Papadakis, Elim. 1992. "Public Opinion, Public Policy and the Welfare State." Political Studies 40(1):21-37.

Patashnik, Eric M, and Julian E Zelizer. 2013. "The Struggle to Remake Politics: Liberal Reform and the Limits of Policy Feedback in the Contemporary American State." Perspectives on Politics 11(04):1071-1087.

Pearl, Judea. 2009. Causality: Models, Reasoning and Inference. 2nd ed. New York, NY, USA: Cambridge University Press.

Pierson, Paul. 1993. "When Effect Becomes Cause: Policy Feedback and Political Change." World Politics 45(4):595-628.

. 1994. Dismantling the Welfare State? Reagan, Thatcher and the Politics of Retrenchment. Cambridge: Cambridge Univ Press.

. 1996. "The New Politics of the Welfare State." World Politics 48(2):143-179.

. 1998. "Irresistible Forces, Immovable Objects: Post-Industrial Welfare States Confront Permanent Austerity." Journal of European Public Policy 5(4): 539-560.

- 2000. "Increasing Returns, Path Dependence, and the Study of Politics." The American Political Science Review 94(2):251-267.

. 2004. "Positive Feedback and Path Dependence." In Politics in Time: History, Institutions and Social Analysis, Princeton, NJ: Princeton University Press, 17-53.

Poterba, James M. 1995. “Capital Budgets, Borrowing Rules, and State Capital Spending.” Journal of Public Economics 56(2):165-187.

Raven, Judith, Peter Achterberg, Romke van der Veen, and Mara Yerkes. 2011. “An Institutional Embeddedness of Welfare Opinions? The Link Between Public Opinion and Social Policy in the Netherlands (1970-2004)." Journal of Social Policy 40(2):369-386.

Rothstein, Bo. 1998. Just Institutions Matter: The Moral and Political Logic of the Universal Welfare State. Cambridge: Cambridge University Press.

Schakel, W., Burgoon, B., Hakhverdian, A., 2020. Real but Unequal Representation in Welfare State Reform. Polit. Soc. 0032329219897984. https://doi.org/10.1177/0032329219897984

Schmidt-Catran, Alexander W, and Dennis C Spies. 2016. "Immigration and Welfare Support in Germany." American Sociological Review 81(2):1-20.

Schmitt, Carina, Hanna Lierse, Herbert Obinger, and Laura Seelkopf. 2015. "The Global Emergence of Social Protection: Explaining Social Security Legislation 1820-2013.” Politics \& Society 43(4):503-524.

Schumacher, Gijs. 2013. "When Does the Left Do the Right Thing? A Study of Party Position Change on Welfare Policies." Party Politics 153:68-79. 
Schwander, Hanna, and Silja Häusermann. 2013. "Who Is in and Who Is out? A Risk-Based Conceptualization of Insiders and Outsiders.” Journal of European Social Policy 23(3):248269.

Scruggs, Lyle, and James P. Allan. 2006. "The Material Consequences of Welfare States: Benefit Generosity and Absolute Poverty in 16 OECD Countries." Comparative Political Studies 39(7):880-904.

Skocpol, T., Williamson, V., 2016. The Tea Party and the Remaking of Republican Conservatism. Oxford University Press.

Somers, Margaret R., and Fred Block. 2005. "From Poverty to Perversity: Ideas, Markets, and Institutions over 200 Years of Welfare Debate.” American Sociological Review 70(2):260 87.

Soroka, Stuart N, and Christopher Wlezien. 2005a. "Opinion Representation and Policy Feedback: Canada in Comparative Perspective." Canadian Journal of Political Science 37(3):531-559. . 2005b. "Opinion-Policy Dynamics: Public Preferences and Public Expenditure in the United Kingdom." British Journal of Political Science 35(4):665-689. . 2010. Degrees of Democracy: Politics, Public Opinion and Policy. Cambridge: Cambridge University Press.

Soss, Joe, and Sanford F Schram. 2007. "A Public Transformed? Welfare Reform as Policy Feedback." The American Political Science Review 101(1): 111-127.

Stephens, John D. 2015. "Revisiting Pierson's Work on the Politics of Welfare State Reform in the Era of Retrenchment Twenty Years Later.” PS: Political Science \& Politics 48(2):274-278.

Stimson, James A, Michael B Mackuen, and Robert S Erikson. 1995. "Dynamic Representation." The American Political Science Review 89(3):543-565.

Teorell, Jan et al. 2017. The Quality of Government OECD Dataset, Version Jan17. Gothenburg: University of Gothenburg: The Quality of Government Institute.

Thelen, Kathleen. 2014. Varieties of Liberalization and the New Politics of Social Solidarity. Cambridge: Cambridge University Press.

Weaver, Kent. 2010. "Paths and Forks or Chutes and Ladders?: Negative Feedbacks and Policy Regime Change." Journal of Public Policy 30(2):137-162.

Wendt, C., Mischke, M., Pfeifer, M., 2011. Welfare States and Public Opinion: Perceptions of Healthcare Systems, Family Policy and Benefits for the Unemployed and Poor in Europe. Edward Elgar Publishing.

Wilensky, Harold L. 1975. The Welfare State and Equality: Structural and Ideological Roots of Public Expenditures. Berkeley, Los Angeles and London: Univ of California Press.

Wlezien, Christopher. 1995. "The Public as Thermostat: Dynamics of Preferences for Spending." American Journal of Political Science 39(4):981-1000.

. 2004. "Patterns of Representation: Dynamics of Public Preferences and Policy." The Journal of Politics 66(1):1-24.

Wlezien, Christopher, and Stuart Soroka. 2012. "Political Institutions and the Opinion-Policy Link." West European Politics 35(6):1407-1432. 


\section{ONLINE APPENDIX}

A note to the reader: all data and code will be freely shared upon publication of this article either on this journal's server or using the Open Science Framework. Reviewers can view an anonymous version of the code here: https://osf.io/r3vj5/?view_only=a061ff7b00374f24882248cb2037ddbe 


\section{Online Appendix Table of Contents}

Figure 1. Pension Replacement Rates, 1930-2010 3

Table 1. Descriptive Statistics 4

Table 2. Index Scoring for Social Policy Preferences 5

Table 3. Full Metric Results for Simultaneous Feedback Models 6

Table 4. Robustness of Models, Residual Constrained 7

Figure 6. Simultaneous Feedback Model - Extent of Labor Market Policy 8

Note on "Public Opinion" 
Figure 1. Pension Replacement Rates in 17 Countries, 1930-20151

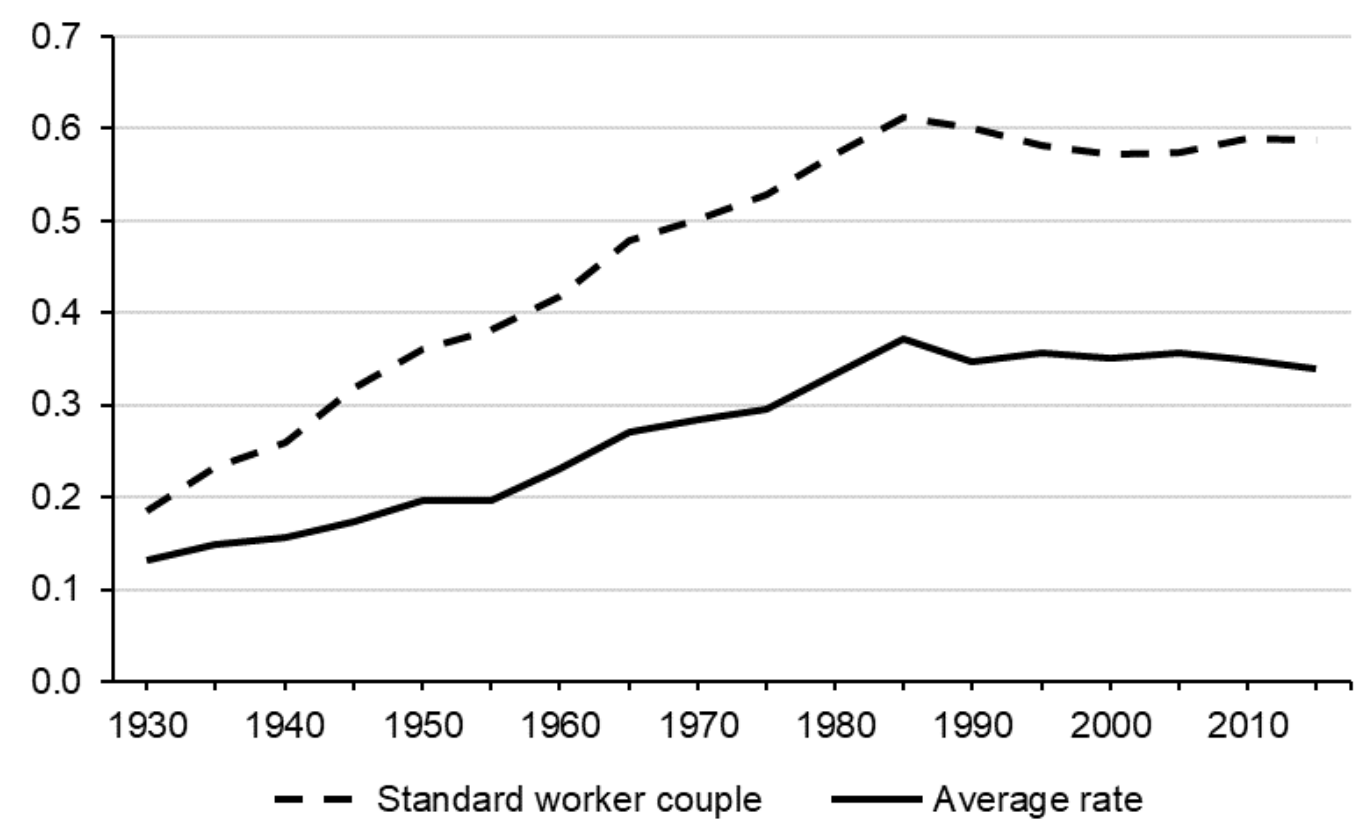


Table 1. Descriptive Statistics

\begin{tabular}{|c|c|c|c|c|c|c|c|c|}
\hline Variable & \multicolumn{2}{|c|}{ Obs } & Mean & Std. Dev. & Min & \multicolumn{2}{|c|}{$\operatorname{Max}$} & Source \\
\hline \multicolumn{9}{|l|}{ Public Opinion (endogenous) } \\
\hline \multicolumn{2}{|l|}{ Support for A Social Welfare State } & 51 & -0.21 & 0.40 & -0.94 & & 0.64 & ISSP \\
\hline \multicolumn{9}{|l|}{ Social Policy (endogenous) } \\
\hline \multicolumn{2}{|l|}{ Size of the Welfare State } & 51 & -0.19 & 0.95 & -1.51 & & $1.92 \mathrm{OE}$ & ECD/Fraser \\
\hline \multicolumn{2}{|l|}{ Extent of Labor Market Policy } & 51 & -0.22 & 0.89 & -1.55 & & 1.55 & Fraser \\
\hline \multicolumn{9}{|l|}{ Independent Variables } \\
\hline Aged & & 51 & 15.65 & 3.02 & 10.65 & & 26.02 & QoG \\
\hline Unemployment & & 51 & 7.58 & 4.09 & 3.20 & & 22.68 & QoG \\
\hline GDP per capita (in k 2016 intl. \$) & & 51 & 36.52 & 15.27 & 14.10 & & 80.99 & QoG \\
\hline Right & & 51 & 0.55 & 0.50 & 0.00 & & 1.00 & QoG \\
\hline Collective Veto & & 51 & -0.14 & 0.96 & -2.02 & & 0.76 & QoG \\
\hline Female LFP & & 51 & 54.57 & 8.01 & 33.56 & & 69.50 & QoG \\
\hline Correlations & [1] & [2] & [3] & [4] & [5] & {$[6]$} & [7] & [8] \\
\hline Support for A Social Welfare State [1] & 1 & & & & & & & \\
\hline Size of the Welfare State [2] & 0.40 & 1 & & & & & & \\
\hline Extent of Labor Market Policy [3] & 0.52 & 0.86 & 1 & & & & & \\
\hline Aged [4] & 0.07 & 0.56 & 0.28 & 1 & & & & \\
\hline Unemployment [5] & 0.52 & 0.28 & 0.35 & -0.03 & 1 & & & \\
\hline GDP per capita (k)) [6] & -0.27 & 0.00 & -0.11 & 0.25 & -0.54 & 1 & & \\
\hline Right [7] & -0.03 & -0.08 & -0.15 & 0.17 & -0.16 & 0.16 & 1 & \\
\hline Collective Veto [8] & 0.15 & 0.29 & 0.38 & 0.25 & -0.15 & 0.26 & 0.01 & 1 \\
\hline Female LFP [9] & -0.38 & -0.05 & -0.18 & 0.08 & -0.55 & 0.57 & -0.03 & 0.07 \\
\hline
\end{tabular}


Table 2. Index Scoring for Social Policy Endogenous Variables

\begin{tabular}{|c|c|c|c|c|}
\hline Reflective Scales & & Coef. & SE & Factor Loading \\
\hline \multicolumn{5}{|c|}{ Scale: Welfare State Size } \\
\hline \multirow[t]{2}{*}{ govconsp } & & 0.942 & 0.067 & 0.604 \\
\hline & constant & 5.845 & 0.069 & \\
\hline \multirow[t]{2}{*}{ govtransp } & & 1.301 & 0.057 & 0.865 \\
\hline & constant & 5.211 & 0.067 & \\
\hline \multirow[t]{2}{*}{$\operatorname{soc} x$} & & 4.261 & 0.185 & 0.874 \\
\hline & constant & 21.335 & 0.215 & \\
\hline \multicolumn{5}{|c|}{ Scale: Labor Market Policy } \\
\hline \multirow[t]{2}{*}{ regjobp } & & 1.019 & 0.076 & 0.591 \\
\hline & constant & 5.508 & 0.076 & \\
\hline \multirow[t]{2}{*}{ regbargp } & & 1.507 & 0.072 & 0.878 \\
\hline & constant & 4.443 & 0.076 & \\
\hline \multirow[t]{2}{*}{ reghoursp } & & 1.070 & 0.103 & 0.475 \\
\hline & constant & 3.799 & 0.099 & \\
\hline \multicolumn{4}{|c|}{ covariance(Welfare Size*Labor Market) } & 0.785 \\
\hline
\end{tabular}

NOTE: As variables are on different scales I use predictive scaling to weight them appropriately. This is not intended as a measurement model. Variables are: govconsp (Fraser government consumption); govtransp (Fraser transfers and subsidies); socx (OECD social spending as \% of GDP); regjobp (Fraser hiring/firing protection); regbargp (Fraser institutionalized collective bargaining); reghoursp (Fraser hours regulations); the variable for Fraser wage regulation correlates highly with these three but had too much missing data to use. 
Table 3. Full Metric Results for Simultaneous Feedback Models

\begin{tabular}{lcccc|cccc}
\hline & \multicolumn{3}{c}{ Size of the Social State } & \multicolumn{5}{c}{ Extent of Labor Market Policy } \\
& M0 & M1 & M2 & M3 & M10 & M11 & M12 & M13 \\
\hline Social Policy <-- & & & & & & & & \\
Public Opinion & -0.403 & 0.390 & 0.000 & 0.000 & 0.547 & 0.370 & 0.000 & 0.000 \\
Aged (65+) & 0.186 & 0.177 & 0.184 & 0.185 & 0.084 & 0.086 & 0.088 & 0.091 \\
Unemployment(\%) & 0.083 & 0.048 & 0.065 & 0.064 & 0.050 & 0.058 & 0.074 & 0.074 \\
GDP (per capita/k) & -0.011 & -0.003 & -0.007 & -0.007 & -0.003 & -0.005 & -0.008 & -0.008 \\
Right Party Control & -0.245 & -0.286 & -0.268 & -0.269 & -0.307 & -0.297 & -0.276 & -0.278 \\
Veto Points & -0.592 & -0.695 & -0.646 & -0.620 & -0.365 & -0.338 & -0.293 & -0.348 \\
& & & & & & & & \\
Public Opinion <-- & & & & & & & & \\
Social Policy & 0.032 & 0.058 & 0.032 & 0.000 & 0.072 & 0.063 & 0.067 & 0.000 \\
Unemployment(\%) & 0.033 & 0.032 & 0.033 & 0.036 & 0.030 & 0.031 & 0.030 & 0.036 \\
GDP (per capita/k) & -0.005 & -0.006 & -0.005 & -0.005 & -0.005 & -0.005 & -0.005 & -0.005 \\
RightParty Control & 0.032 & 0.038 & 0.033 & 0.030 & 0.044 & 0.042 & 0.042 & 0.029 \\
Female LFP (\%) & -0.014 & -0.013 & -0.013 & -0.013 & -0.013 & -0.013 & -0.014 & -0.013 \\
& & & & & & & & \\
Residual covariance & & & & & & & & \\
(Policy*Opinion) & 0.001 & -0.080 & -0.047 & -0.080 & -0.080 & -0.060 & -0.029 & -0.060 \\
& & & & & & & & \\
chi-square & 0.428 & 0.898 & 0.526 & 4.359 & 0.407 & 0.425 & 0.561 & 4.843 \\
df & 14 & 12 & 13 & 11 & 14 & 12 & 13 & 11 \\
test v. M0/M10 & -- & 0.791 & 0.754 & 0.269 & -- & 0.991 & 0.695 & 0.218 \\
M1/M11 v. M2/M12 & -- & 0.542 & -- & -- & -- & 0.712 & -- & - \\
M1/M11 v. M3/M13 & -- & -- & - & 0.063 & -- & - & - & 0.036 \\
CFI & 1.000 & 1.000 & 1.000 & 0.991 & 1.000 & 1.000 & 1.000 & 0.966 \\
RMSEA & 0.000 & 0.000 & 0.000 & 0.042 & 0.000 & 0.000 & 0.000 & 0.064 \\
AlC & 1448 & 1444 & 1446 & 1446 & 1456 & 1452 & 1454 & 1454 \\
BIC & 1475 & 1467 & 1471 & 1467 & 1483 & 1475 & 1479 & 1476 \\
\hline
\end{tabular}

NOTE: The equal fit test rows compare the current model of that column with the model listed in that row. For example, "M0 | M10" row compares every model under size of the welfare state to M0 and every model under extent of labor market policy to M10, and so on for "M2|M12" and "M3 | M13". I do not add a row for "M1 | M11" because it would be redundant with the information in the columns under M1 and M11 respectively. "test v. M0/M10" suggests that all models do not fit the data significantly worse than the baseline models (because $\mathrm{p}>0.05$ ). This means that all could be preferred to the baseline model as they are more parsimonious. "M1/M11 v. M2/M12" suggests that M1 and M11 do not fit worse than M2 and M12 respectively, thus leading to a preference for these models. Finally, M1 does not fit worse than M3 but M11 is questionable at $<0.036$. 
Table 4. Robustness of Models under a Zero Residual Covariance Assumption

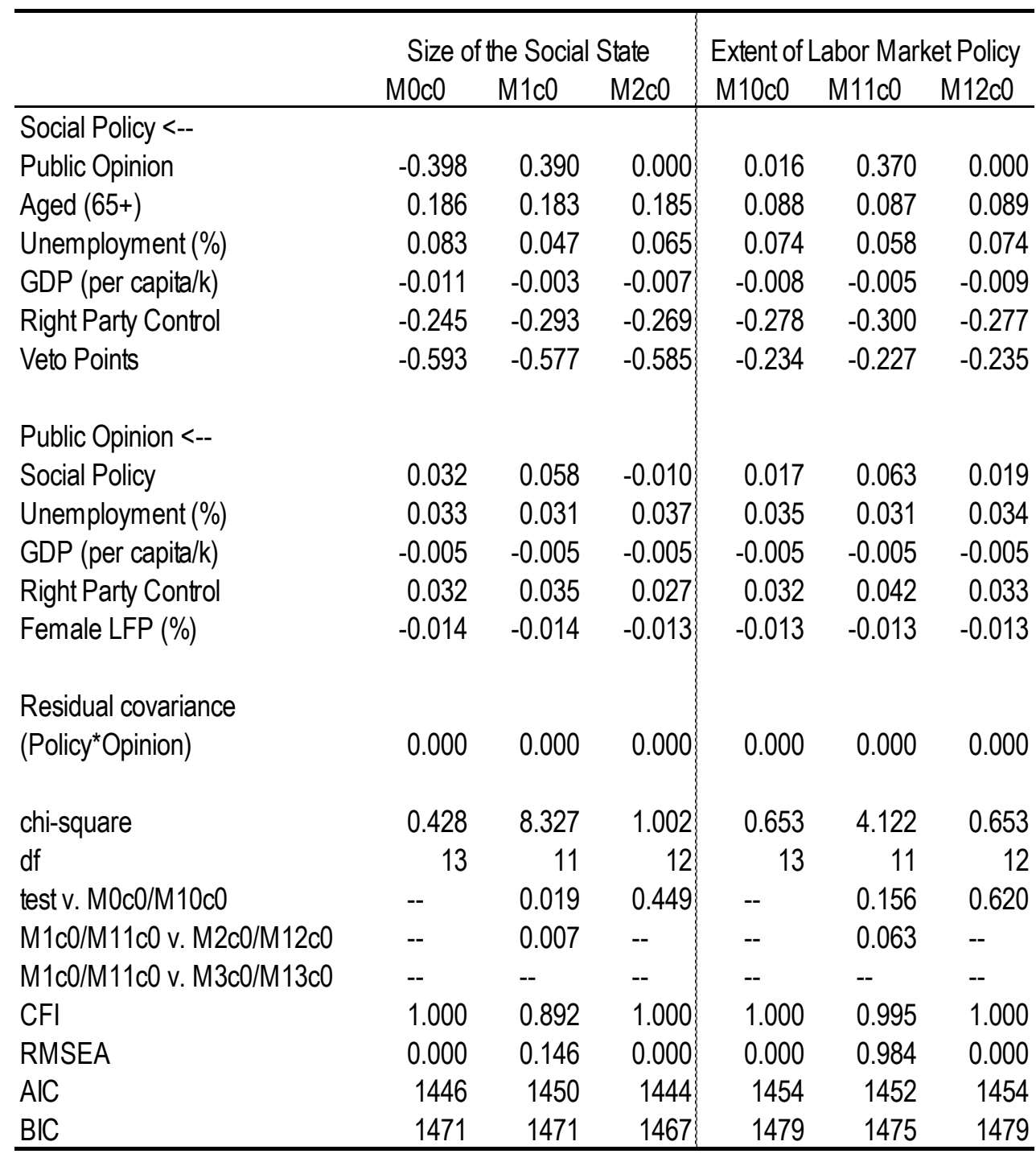

NOTE: M1c0 fits worse for size of welfare state but not worse for extent of labor market policy. I would contend that thermostatic feedback likely explains this because opinion can react negatively to spending and lead to a change in a one-year cycle, but this is not normally possible with labor market policies which normally take time to write and pass, if not implement. So spending and opinion are at equilibrium, but the effect of opinion looks like zero in long-term equilibrium because of short-term negative feedback and long-term positive feedback. 
Figure 6. Simultaneous Feedback Model Testing Bi-directional feedback in Labor Market Policy

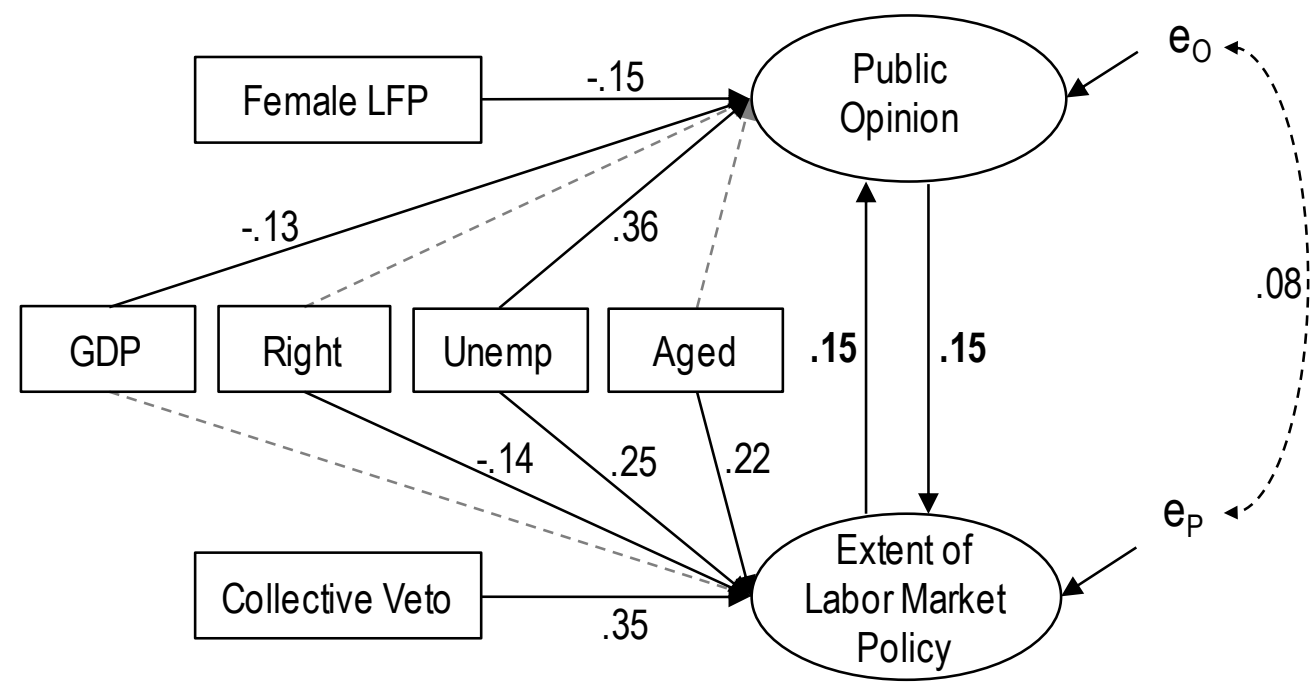




\section{A Note on "Public Opinion"}

I label it "public opinion" in lieu of "mass preferences", "public mood", "attitudes", "public preferences" or other labels. Unlike these other terms, public opinion carries the theoretical suppositions that the public have a special quality in a given society that cause policymaking and societal outcomes. It is not my goal here to resolve the 'does public opinion exist?' debate. I assume that public opinion exists and matters, and therefore that individual responses to survey questions reflect this existence. Whether those questions are appropriate for measuring, what 'are', 'are caused by' or simply 'reflect' public opinion is outside the range of this research. Surveys come with pitfalls, and some argue public opinion requires more than surveys to measure; for example, media messages, public discourse, attention to structural inequalities and etc. (Bourdieu, 1979; Habermas, 1989). None the less, incorporating several survey questions and paying attention to measurement error should provide a triangulation of public opinion, at least in a given year or sampling time period.

\section{References:}

Bourdieu, Pierre. 1979. "Public Opinion Does Not Exist." In Communication and Class Struggle, Volume One, eds. A. Matelart and S. Siegelaub. New York, NY: International General, 124130.

Habermas, Jürgen. 1989. The Structural Transformation of the Public Sphere: An Inquiry into a Category of Bourgeois Society. English Tr. eds. Thomas Burger and Frederick Lawrence. Cambridge, MA: MIT Press. 